Lexis Vol. XLIV (1) 2020: 145-173

\title{
Antihiatismo en español: un problema fonológico entre la preceptiva literaria y la normativa gramatical
}

\author{
Antonio Alcoholado Feltstrom \\ Universitat Jaume I
}

\section{RESUMEN}

La tautosilabación de hiatos mediante sinalefa y sinéresis en el habla española ha quedado registrada por estudiosos de diverso tiempo y lugar. Este trabajo recopila valoraciones de tratadistas desde los campos de la versificación y la gramática, observa la discrepancia que presentan la gramática normativa y la preceptiva literaria en sus valoraciones sobre las articulaciones antihiáticas, $\mathrm{y}$, por último, sugiere un acercamiento entre ambas por medio de la comprensión de una realidad fonológica.

Palabras clave: antihiatismo, versificación, norma, fonología

Anti-hiatus Tendency in Spanish: a Phonological Issue Involving Literary Precept and Normative Grammar

\section{Abstract}

Hiatus resolution in Spanish speech by means of synaloephe and synaeresis has been studied by scholars from varied times and origins. This paper summarizes different authors' evaluations from the disciplines of meters and grammar, notes the disagreement shown by normative grammar and literary preceptive about anti-hiatus pronunciation, and considers a possible reconciliation though the understanding of a phonological reality. Keywords: Anti-hiatus tendency, meters, norm, phonology

https://doi.org/10.18800/lexis.202001.005 


\section{Introducción}

Se denomina antihiatismo (Alcina y Blecua 1975: 417) o tendencia antihiática (Quilis [1993] 1999: 189-190) a la articulación tautosilábica de secuencias vocálicas "cuyo resultado esperable [...] es un hiato" (Real Academia Española y Asociación de Academias de la Lengua Española 2011: 339); esta divergencia entre realidad articulatoria y previsión gramatical se manifiesta en una reflexión, vigente desde antiguo, en el estudio de la gramática y la versificación de nuestra lengua, con diferentes posturas que no parecen ofrecer una conclusión definitiva.

Este trabajo aborda la cuestión en orden cronológico desde la perspectiva de la métrica tradicional, en primer lugar, seguida de la observación gramatical en el campo de la prosodia ${ }^{1}$, para finalmente sugerir una posible conciliación entre las posiciones dispares de la gramática normativa y la preceptiva literaria. Para ello, se ha recurrido a distintos tratados en una y otra disciplina, así como a otros trabajos de interés en el esclarecimiento de aspectos problemáticos en torno a nuestro objeto de estudio; desde el punto de vista de la normativa gramatical, se otorga especial atención a los publicados por la Real Academia Española y la Asociación de Academias de la Lengua Española (en adelante, también RAE y ASALE o, en su conjunto, las Academias).

\section{El antihiatismo en la preceptiva literaria}

La sinalefa y la sinéresis, catalogadas desde la versificación y la gramática como licencias del verso (De Arrúe 1842: 148-149), licencias prosódicas (Monláu 1842: 252), figuras prosódicas (Gómez Hermosilla 1826: 121) o fenómenos métricos (RAE y ASALE 2011:

\footnotetext{
1 Hasta el siglo XIX, la prosodia como disciplina lingüística y la métrica como estudio de la versificación se solapan con frecuencia, como se constatará en las páginas que siguen. Paraíso Almansa (2000: 20-21) nota que en el siglo XX tiene lugar la separación académica entre el estudio de la pronunciación y el del verso, coincidente con el desarrollo de la fonética y la fonología.
} 
353), eran regulares en la versificación latina y perviven en las de las lenguas romances (Lausberg 1998: 230-231); pese a su carácter normativo en el verso latino, que se correspondería también con el habla según testimonio de Cicerón y Quintiliano, conocían excepciones de naturaleza prosódica (Allen 1978: 78).

A lo largo del Medievo, sin embargo, probablemente debido a la influencia de las interpretaciones gramaticales generadas desde la Escuela de York y extendidas por la reforma carolingia (Quilis Merín 1991: 797-798), se aprecia una tendencia a evitar la concurrencia de vocales en la composición de versos en latín (Lozano 2006: 226), para impedir vacilaciones entre hiato y sinalefa, estrategia ya constatada en los versos del mismo Alcuino de York, quien, en casos de contigüidad de vocales, optaba por escandir como hiatos combinaciones que constituían sinalefa en los versos de poetas latinos nativos (Solana Pujalte 1987: 111, 335, 377-379).

Esta tensión entre la influencia de gramáticos británicos, cuyos postulados ganaron prestigio a través del renacimiento carolingio, y la práctica latina normal, perpetuada en las lenguas romances, explica la convivencia de dos sistemas distintos de versificación en la España medieval, uno foráneo y otro autóctono, respectivamente (Cano 1931: 232-233). Mientras el autóctono mantiene la normalidad romance de las articulaciones antihiáticas, el foráneo, que influye en las composiciones cultas, se caracteriza por seguir el precepto de la dialefa, fenómeno métrico hiante que domina la escansión del mester de clerecía (Hanssen 1897: 230; Uría Maqua 1986: 11), a pesar de la presencia significativa de sinalefas en estas composiciones, deslices que, en opinión de Navarro Tomás, delatan la cotidiana pronunciación antihiática de los poetas del mester (Navarro Tomás [1956] 1974: 105). De todos modos, la escansión hiante es norma obligada para los poetas cultos durante el siglo XIII (Uría Maqua 1986: 11-12; Pla Colomer 2019: 25-26).

En el XIV, la convención mantiene la dialefa como precepto, aunque López de Ayala especifica casos en los que prima la sinalefa (Clarke 1995: 129-130) y, de hecho, se registra una presencia creciente de esta a lo largo del siglo (Hanssen 1900: 322-324). En el 
$\mathrm{XV}$, mientras varios autores cultos evitan la concurrencia de vocales en sus versos, Jorge Manrique ya emplea la sinalefa con naturalidad (Clarke 1995: 131-132).

En el siglo XVI, la escansión hiante como norma culta cae completamente en el olvido (Uría Maqua 1986: 12), mientras que la sinalefa característica del sistema autóctono recupera su regularidad. Reflejo de la normalidad de la escansión antihiática en este siglo es el empleo, por parte de Fernando de Herrera, de marca gráfica mediante punto sobre cada una de las vocales implicadas para señalar al lector los casos excepcionales de escansión de esas vocales en sílabas distintas (Blecua 1977: 20-22, 75-76); alude De Herrera a la tradición latina de evitar el hiato "para que el verso no sea hiulco", a la vez que reconoce la propiedad de la dialefa, que describe como "divisiones hechas artificialmente", para expresar aspereza, discordia, división, impedimento, oposición, repugnancia, separación (De Herrera 1580: 139-141). De la descripción de Sánchez de Lima, se desprende que la sinalefa es general en la medida de los versos, aunque alerta de que el oído puede encontrar en ocasiones mayor propiedad en el hiato (Sánchez de Lima 1580: 36-37). Una década más tarde, Díaz Rengifo (1592: 19-20) presenta la sinalefa como recurso sistemático en la escansión e indica algunas circunstancias prosódicas que favorecen el hiato.

Los tratadistas de los siglos XVIII y XIX, según recoge Domínguez Caparrós (1975: 191-205), mantienen el parecer de sus predecesores al respecto, limitando el hiato a circunstancias prosódicas, como son los acentos de especial relevancia en el verso, y a necesidades expresivas, como son la lentitud o la aspereza.

La consulta de trabajos del siglo XIX, en el que prolifera la publicación de tratados de métrica y prosodia, ofrece la misma unanimidad, con los inevitables matices individuales. De Masdéu (1801: 56-61) presenta una serie de excepciones que propician el hiato frente a sinalefa y sinéresis, fundamentalmente relacionadas con acentos; llama la atención que, en casos de aspiración de $h$, que dan lugar a vacilaciones de escansión según distintos autores en composiciones del siglo XVI (Quilis 1984: 50), De Masdéu 
parezca atribuir al arbitrio del poeta la unión silábica o la separación. Gómez Hermosilla (1826: 121-122) presenta la sinalefa como “común, frecuente, y necesaria”, pero encuentra que la sinéresis es tan excepcional como la diéresis, y que el verso en el que no se dé confluencia de vocales, de modo que evita con ello la presencia de fenómenos métricos, "es más armonioso".

González Portilla (1831: 135-139) reafirma la necesidad de la sinalefa tanto en verso como en prosa, insistiendo en el "efecto desagradable" del hiato, que ha de evitarse salvo en aquellos casos en que se acomode a la expresión o cuando la articulación antihiática entre en conflicto con acentos del verso o con la comprensión por parte del oyente.

Bello (1835: 45, 55, 58-62, 115-116) también encuentra la sinalefa común a la prosa o «lenguaje ordinario, de cuya pronunciación no es lícito al poeta alejarse», si bien la sinéresis se da, a su juicio, más en el verso que en la prosa, pero más frecuentemente en cualquier caso que la diéresis; también enumera casos en que se propicia el hiato por razón prosódica o por intención expresiva.

Monláu (1842: 252-253) repite las palabras de Gómez Hermosilla respecto de la sinalefa; en cuanto al hiato, lo describe como “desapacible al oído”. Sinibaldo de Mas (1843: 22, 25) renuncia a explicar los fenómenos métricos, que da por ampliamente conocidos, pero observa que, a diferencia de otros idiomas, en español la sinalefa mantiene los sonidos de las vocales implicadas, aspecto sobre el que también se había pronunciado Bello (1835: 54-55).

Gil de Zárate (1850: 69-71) también encuentra menos propiedad en la sinéresis que en la sinalefa, a la que asigna límites relacionados con el acento; Coll y Vehí $(1856: 54,181)$ considera el hiato, junto con el sonsonete y la cacofonía, "contrarios a la melodía” en su apartado sobre la armonía como cualidad esencial del lenguaje, aunque reconoce su pertinencia paródica para el estilo jocoso; Arpa y López (1888: 51-52) concuerda con Coll y Vehí en la falta de armonía del hiato, al igual que Callejón y Asme (1888: 120, 150, 177-178, 181), quien reitera el carácter normal de la sinalefa limitado por excepciones prosódicas; Milá y Fontanals (1888: 254, 380, 389) atribuye 
"discordancia” al hiato mientras que considera la sinalefa "una regla necesaria y obligatoria, de modo que existe verdadera licencia en los pocos casos en que deja de conocerse”. López Bastarán (1889: 96, 149-151) mantiene el juicio de Coll y Vehí, Arpa y López, y Callejón y Asme en lo que se refiere al hiato, al que vuelve a calificar de "desagradable", como González Portilla, y se alinea con Bello en la consideración de la sinéresis como excepcional, a diferencia de la sinalefa; también Marroquín (1893: 34) incluye el hiato como “defecto” que se opone a la melodía. Benot (1898: 281-282, 286) se muestra reacio a la sinéresis cuando una de las vocales implicadas es tónica, al mismo tiempo que juzga la diéresis como licencia "indisculpable las más veces” y la articulación en hiato de combinaciones de vocales medias átonas en interior de palabra (caso de la voz teoría articulada en cuatro sílabas: te-o-rí-a) como "licencia vituperable".

Ya en el siglo XX, Carpintero Moreno (1906: 210) mantiene la denominación de "defecto" para referirse al hiato, como hiciera Marroquín; Jaimes Freyre (1919: 94-95) identifica hiato y sinalefa, respectivamente, con "excepción” y "regla”, mientras censura la diéresis y afirma que la sinéresis resulta de "ignorancia prosódica” o de "vicio nacional o regional de pronunciación”; en la misma línea que Milá y Fontanals, insiste en que la sinalefa no es "licencia” sino "necesidad del idioma".

Navarro Tomás (1959: 13-14) atribuye a la sílaba en el verso español el valor oral que le corresponde en la pronunciación normal de nuestra lengua (en consonancia con la observación de Bello de que el poeta ha de ser fiel a la pronunciación corriente) en oposición al valor visual que adquiere en la escritura, e insiste en la "tendencia general" al antihiatismo, limitada en casos que, a su juicio, no se pueden ajustar a "reglas simples y precisas", aunque la influencia de las posiciones acentuales es primordial (Navarro Tomás [1956] 1974: 105).

De Balbín (1968: 71) sostiene, como Milá y Fontanals y Jaimes Freyre, que la sinalefa no es licencia sino "hecho lingüístico general y necesario" tanto "en la prosa como en el verso"; afirma que el acento la "dificulta—aunque en pocos casos llega a impedirla—”. 
Spang (1983: 33, 35-37) tiene en cuenta la diferencia entre ortografía y dicción señalada por Navarro Tomás y asume que la presencia mayoritaria de la sinalefa en la versificación se debe a su carácter natural en el habla, al contrario de las realizaciones hiantes.

Quilis (1984: 52) encuentra una "clara jerarquización" entre los fenómenos métricos según su frecuencia en la lengua, de modo que sinéresis y sinalefa, a su juicio, "son fenómenos corrientes y prácticamente constantes en el habla", frente a las articulaciones hiantes, que "constituyen una excepción".

Cerrando el siglo, Torre Serrano (1999:39-40) destaca que la sinalefa y la sinéresis son "hechos de habla", mientras Paraíso Almansa (2000: 115-118) insiste en las diferencias entre pronunciación y escritura, y, en la línea de Gómez Hermosilla, Bello, Gil de Zárate y López Bastarán, discrepa del parecer de Quilis al respecto de la sinéresis, que considera menos favorable que la sinalefa. Desde el campo de la versología, Bělič $(2000: 32-33,134,137,513)$ plantea el caso de la sinalefa que se impone sobre elementos de demarcación entonativa (acentos de intensidad, signos de puntuación) como posible ejemplo de deformación del idioma según definen el verso los formalistas, pero concluye que, en español, las señales demarcativas son débiles y la sinalefa un elemento característico, natural "tal vez con excepción de la sinalefa entre dos réplicas en el verso teatral”.

Ya en el siglo en curso, Domínguez Caparrós (2001: 113-114, 204-205, 400, 404) compendia que se desaconseja el hiato en el verso español, a menos que un acento "muy marcado" lo favorezca, que en la realización de sinéresis influyen "factores de índole gramatical y emocional", y que la sinalefa es "fenómeno normal y general" en la pronunciación de nuestra lengua.

García Calvo (2006: 79-80) diferencia la sílaba rítmica, exclusiva de la producción oral, de la gramatical, explicando esta última como abstracción convencional, basada en la realidad física de la sílaba rítmica, que dificulta la comprensión de la "solución de problemas de intersilabación entre dos palabras"; ilustra la discordancia entre sílaba rítmica y gramatical con la sinalefa, que identifica como "norma en el habla de lenguas como el español", y la sinéresis. 
Torre Serrano (2013: 200-203) ha vuelto a insistir en las diferencias entre dicción y representación gráfica, y ha reiterado la artificiosidad de la dialefa, que se debe evitar por cacofónica salvo cuando se ajusta al propósito expresivo, y la naturalidad de la sinalefa, que "lejos de ser una licencia" es, por el contrario, "un fenómeno fonético que se da habitualmente en el verso y en el lenguaje ordinario".

En resumen, a pesar de la influencia en la versificación culta medieval de una práctica de escansión foránea, originada en Britania, “moda ajena y pasajera” (Baehr 1984: 59) más notable en el siglo XIII y progresivamente desatendida en los dos siguientes, la versificación española sigue de manera preceptiva la articulación antihiática entre palabras, es decir, la sinalefa.

En interior de palabra, o sinéresis, no hay unanimidad entre los tratadistas consultados en este estudio: frente a Quilis, que comenta específicamente su carácter regular, encontramos la discrepancia de Gómez Hermosilla, Bello, Gil de Zárate, López Bastarán, Benot, Jaimes Freyre, Torre Serrano y Paraíso Almansa. Entre estos, Benot indica el acento de intensidad en una de las vocales implicadas como impedimento, mientras que, en el caso de vocales átonas, censura que se mantenga el hiato.

A este respecto, coinciden todos los tratadistas consultados en que acentos prominentes del verso constituyen límite prosódico para la sinalefa, aunque De Balbín atenúa esta capacidad del acento para impedirla y Bělič sostiene que se trata de un elemento débil en nuestro idioma; De Herrera, De Masdéu, González Portilla, Bello, Coll y Vehí, y Torre hacen mención específica de propósitos expresivos que pueden favorecer el hiato.

Díaz Rengifo, De Masdéu, Bello, entre otros, detallan las condiciones prosódicas que impiden la sinalefa, mientras que Navarro Tomás indica la dificultad de determinar de manera definitiva las circunstancias en que puede o no darse la articulación antihiática; a este respecto, declara en su manual de pronunciación que los intentos de prosodistas por establecer reglas sobre la sinalefa o la sinéresis han fracasado, dada la libertad lingüística de los hablantes 
para realizarlas o no (1918: 117), lo que implicaría que los factores expresivos primasen sobre los prosódicos.

Encontramos valoraciones negativas del hiato como "desagradable” (González Portilla, López Bastarán), “desapacible” (Monláu), "defecto" (Marroquín, Carpintero Moreno), frente a la calificación de "necesaria" que se otorga a la sinalefa (Milá y Fontanals, Jaimes Freyre, De Balbín).

De Herrera conecta la práctica normal de la sinalefa en la versificación española con la tradición latina, ilustrando la continuidad romance del antihiatismo; Coll y Vehí, Arpa y López, y Marroquín señalan el hiato como ruptura de la melodía, una de las cuatro bases fundamentales para el "estilo grato" en la composición literaria según Dionisio de Halicarnaso, cuya obra, que se puede considerar una "fono-estilística de la recepción", llegó a España durante el Renacimiento (López Grijera 1994: 350-351, 355). Navarro Tomás, Paraíso Almansa, Torre Serrano y García Calvo atienden a la divergencia entre realización oral y representación escrita.

En definitiva, se desprende de los tratadistas consultados que, en la preceptiva literaria, el antihiatismo, concretamente su manifestación mediante la sinalefa, es normal y natural en la pronunciación de nuestra lengua y, por ello, se refleja en la versificación.

\section{El antihiatismo en la normativa gramatical}

En la gramática inaugural del castellano, Nebrija dedica el séptimo capítulo de la parte de prosodia (libro II) en su gramática a la sinalefa, que considera frecuente tanto en la versificación como en el habla y describe como elisión de una de las vocales (Nebrija 1492)2.

En el siglo XVI, el Anónimo de Lovaina $(1555)^{3}$ describe el diptongo como "voz compuesta del sonido de dos vocales diferentes, proferida a un mismo tiempo y aliento", que presenta doce maneras, entre las que cuenta la combinación ao, "en que la a se

\footnotetext{
Sin numeración de páginas en el original.
}

3 Tampoco cuenta con páginas numeradas. 
toca más que la o", como en los ejemplos "sarao, Vilbao"; acaba su exposición de las combinaciones vocálicas aludiendo al entendimiento de los poetas en esta materia. López de Velasco (1582: 305-306) también incluye ao entre los diptongos, con el ejemplo "nao"; comenta, en lo que respecta a las combinaciones ae, ea, oe, que "unas veces se juntan en diptongo, y otras no", dependiendo del acento de intensidad.

En el siglo XVII, Correa (1625: 36-38, 142) denomina mayores a las vocales nucleares y menores o diptongales a las marginales, en casos de diptongo y triptongo; especifica que "la sinalefa solo acontece en las vocales mayores a, e, o" y percibe que las vocales implicadas en ella suenan "la postrera más ordinariamente, la de antes menor”. Distingue entre sinalefa y sinéresis, a la que, a su vez, diferencia del "apóstrofe" o elisión, y explica también la diéresis sin emitir juicios de propiedad.

Villar (1651: 158-159), ya al final de su tratado, destaca la predominancia del antihiatismo por medio de la sinéresis y, como Correa, percibe en las combinaciones tautosilábicas de vocales que "la primera se pronuncia con tal velocidad, que por sí sola no hace sílaba; así de ambas se hace una sola, y siempre se cuenta una sola en los versos"; para ilustrar el peso del acento, recurre a la voz "poesía, donde el poe pasa siempre por una sílaba, y el sía por dos”.

En el siglo XVIII, la primera Ortografía de la Real Academia (1741: 238-244) encomienda la discusión sobre grupos vocálicos a la gramática, pero dedica un apartado a la sinalefa, que describe más como elisión de la primera vocal implicada: "La vocal última de una dicción se consume o se oculta por la primera vocal de la dicción siguiente"; nota su regularidad en la versificación: "Esta figura la conoce muy bien la poesía española”; y reconoce su carácter común en el habla, aunque insistiendo en los encuentros de vocales idénticas: "En la lengua es tan natural, que el más ignorante la comete, sin conocerlo, ya sea por evitar la cacofonía, ya por la dificultad que naturalmente se encuentra en repetir una misma vocal". Indica que, a diferencia de otras lenguas romances en las que se emplea apóstrofe, en español la sinalefa no tiene reflejo en la escritura, salvo 
contracciones que se han regularizado, como es el ejemplo de preposición más artículo al y del.

Sin embargo, la primera Gramática de la Academia (1771: 55, 206, 229-230) solo menciona la sinalefa como figura de dicción, clasificada como metaplasmo, entre alteraciones como la metátesis, la aféresis, la síncopa, la apócope y la epéntesis; la explica como elisión, ilustrada en las contracciones entre preposición y artículo al y del.

En el siglo XIX, Calleja (1818: 118) también incluye la sinalefa como figura de dicción junto a síncopa, apócope, etc. y la explica como elisión de la primera vocal.

Por el contrario, García del Pozo $(1825: 62-63,101)$ constata que "en castellano no hay vocal que no se pronuncie a veces unida en una sílaba con cualquiera de las otras cuatro vocales”, y, a la manera de los tratadistas del XVI, presenta articulaciones antihiáticas de combinaciones entre las vocales medias y la abierta bajo la denominación de diptongos con los siguientes ejemplos, entre otros: aa "contraataques"; ae "recae, tráelo, portaestandarte"; ao "bacalao, esperaos"; ea "espoleadura, vicealmirante"; ee "reedificar"; oa "Joaquín, almohada"; oe "Goicoechea"; oo "decimooctavo"; especifica que sus ejemplos se centran en interior de palabra, pero que entre palabras "se hallan con más frecuencia, especialmente en el verso", denominando indistintamente sinéresis o sinalefa a los dos casos. En lo que respecta a marcas gráficas para la lectura, siguiendo la línea de De Herrera en sus Anotaciones, estima que, por "frecuentísima", la sinéresis (o sinalefa) no requiere puntuación que la indique, al contrario que la diéresis (o dialefa), que señala, de manera inversa a como hizo De Herrera, con un punto debajo de cada vocal implicada.

De Sicilia (1832: 214, 218-222) reitera el "efecto desagradable" del hiato a menos que se ajuste a condicionante acentual o a propósito expresivo, por lo que el habla, para evitar dicho efecto, se sirve de la articulación antihiática mediante sinalefa y sinéresis.

Salvá ([1827] 1852: 416) observa que la sinalefa "no debe reputarse como licencia poética, porque aun en el habla común pronunciamos en semejantes casos las dos vocales como si formaran diptongo", 
aunque alude al acento y a la intención expresiva como excepciones a la articulación antihiática. Martínez López (1841: 202, 205-206) se manifiesta expresamente en contra de lo expuesto por Salvá y niega la articulación en una misma sílaba de vocales medias o abierta, salvo en los casos de terminación átona -eo, -ea, -oe, por ejemplo, “área”, "línea”, “purpúreo”, “etéreo”, "héroe”, entre otros.

De Arrúe (1842: 148-149), como la Real Academia y Calleja antes que él, agrupa sinalefa y sinéresis entre los metaplasmos, que él denomina "licencias del verso", y explica la sinalefa como elisión de la primera vocal implicada. Ballot (1845: 251, 254, 297), que incluye la sinalefa entre "figuras gramaticales" para un habla "que se aparta del uso común”, primero la describe como elisión, pero más adelante expresa que pueden articularse las dos vocales implicadas "formando una especie de diptongo".

Fernández Monje (1854: 237-238, 243) clasifica los fenómenos métricos entre las "figuras de sintaxis": "por contracción”, la sinalefa; "por alteración prosódica”, la sinéresis y la diéresis. Distingue entre sinalefa suave, entre vocales átonas, y fuerte, cuando implica vocales tónicas o más de dos. Al tratar de la eufonía, expresa que tanto han de evitarse las sinalefas fuertes como el hiato, "sonidos hiulcos o semejantes a un bostezo".

La “nueva edición” de la gramática de la Real Academia, de 1854, solamente menciona la sinalefa, de nuevo descrita como elisión de una de las vocales, bajo la denominación de contracción, entre las figuras de dicción ya contempladas en las impresiones anteriores; alude a la autoridad "de los buenos escritores” como guía en el uso de estas figuras (RAE 1854: 135-136).

En la siguiente "nueva edición, corregida y aumentada" de la gramática de la Academia, la de 1870, la primera que contiene una parte dedicada a la prosodia, advierte la Academia de que se trata de una aproximación que aspira a seguir completando en estudios posteriores; repara en las diferencias entre el habla y la representación gráfica al considerar que las reglas de la pronunciación solo pueden aprenderse a través del ejemplo de lo que se oye y toma por modelo la pronunciación de "la gente culta de Castilla" (RAE 1870: xv, 287). 
Contempla esta primera prosodia de la Real Academia la escala de sonoridad para explicar las combinaciones tautosilábicas de vocales; $i$ y $u$, por ser las menos sonoras, forman diptongo con las demás, mientras que la elevada sonoridad de las medias y abierta reduce la frecuencia de diptongos entre estas; sin embargo, la circunstancia de que $e$ se halle en el centro de la escala de sonoridad, especifica la Academia, da lugar a combinaciones tautosilábicas entre esta y las otras dos abiertas, que denomina cuasi diptongos que el uso transmite a los hablantes. En nota al pie, anuncia la inminente publicación de un Diccionario de la rima, en el que se especifican estos cuasi diptongos (RAE 1870: 296-297). No hemos hallado rastro de dicho diccionario. En 1872, se publicó en París un volumen que contenía las voces del diccionario de la Academia y un diccionario de la rima, en el que no se encuentra sin embargo, referencia alguna a los referidos cuasi diptongos (López Pelegrín, De Oliva y Peñalver 1872).

Salleras (1876: 246, 334-335, 403) también describe la sinalefa como elisión y la engloba, junto a diéresis y sinéresis, entre los metaplasmos bajo el nombre de licencias o figuras; al mismo tiempo, designa el hiato como "disonancia" que ha de evitarse en favor de la melodía.

Eduardo de la Barra (1894) dedica un libro completo al estudio de fenómenos métricos como problemas de fonética. Se propone culminar las reglas establecidas por autores como Bello o Benot, juzgando que el uso de hiato y sinalefa en la tradición poética española es "tan contradictorio que no forma ley", por lo que desdeña la autoridad de la versificación en el estudio de las combinaciones vocálicas; tampoco el "buen uso", que atribuye a los entendidos en la materia y a la Real Academia, ni el "oído", apreciación que varía entre personas y regiones, sirven, a su juicio, para guiarse en el estudio de estos problemas; sus reglas atienden principalmente al acento de intensidad, y muestra los casos en que, a su parecer, impiden la articulación en una misma sílaba (De la Barra 1894: 11-13, 31, 38, 42-43, 49-50).

Añade De la Barra la observación de que, mientras los diptongos se articulan sin afectar la identidad de las vocales, en las 
articulaciones mediante sinéresis, por el contrario, las vocales medias se transforman en cerradas: caus por “caos”, puesía por "poesía”, por ejemplo, por lo que establece que ha de articularse hiato en estas voces; sin embargo, admite la tautosilabación sin alteración de las vocales medias en otras como "beatitud" o "leopardo"; declara que ha de articularse con diéresis, en tres sílabas, "héroe", pero no “óleo”, donde encuentra dos sílabas y sinéresis (De la Barra 1894: 51-53, 57, 59-63). No oculta, en cualquier caso, que, ante la duda, opta por el criterio de su preferencia personal (De la Barra 1894: 94).

En lo que respecta a la sinalefa, por el contrario, no aprecia De la Barra alteración en la identidad de las vocales medias; contempla, también, que esta queda limitada por circunstancias acentuales (De la Barra 1894: 122-125, 134-137).

En el mismo comienzo del siglo XX, Navarro y Ledesma (1901: $29,32,44)$ identifica en la pronunciación verso y prosa, y declara la sinalefa "ley en la lengua castellana"; juzga la sinéresis, sin embargo, "desagradabilísima al oído, y debe ser a todo trance evitada", mientras que no ofrece valoración sobre la diéresis, afirma que "el hiato suele hacer flojos los versos” y que, si no está justificado, debe evitarse en la prosa.

En su Manual de pronunciación española, que incorpora evidencia instrumental del laboratorio de fonética del Centro de Estudios Históricos, Navarro Tomás (1918: 115-117) destaca la importancia de los mecanismos de sinéresis y sinalefa en el conocimiento de nuestra lengua; atiende al proceso fonético que modifica a las vocales agrupadas en una misma sílaba, que describe como "íntima compenetración, en que cada una de ellas, [...] sin dejar de aparecer distintas entre sí, pierde algo de su carácter”; y reconoce vacilaciones entre la articulación hiante y la antihiática según “circunstancias históricas, analógicas o eruditas” o por libertad expresiva del hablante, si bien insiste en que la tendencia preferente es la antihiática; como ya hemos indicado en la sección anterior, afirma don Tomás Navarro Tomás que, por esa libertad individual en cada situación, los intentos de prosodistas por establecer reglas sobre los fenómenos métricos han fracasado. 
En la tercera edición del Manual, Navarro Tomás ([1918] 1926: 145) continúa reflexionando sobre el antihiatismo al formular como principio fundamental de la reducción de vocales a grupos silábicos el hecho lingüístico de que dos o más vocales pueden articularse en una misma sílaba, si no media impedimento fisiológico.

La Real Academia, en la parte de prosodia de su gramática de 1920, establece que toda combinación de vocales medias entre sí o con abierta se corresponde con hiato; admite la articulación antihiática mediante sinalefa y sinéresis, pero especifica que estas obedecen a "las leyes de acento y ritmo, las cuales nada tienen que ver con la ley gramatical de los diptongos y triptongos", con lo que deja el antihiatismo sin explicación gramatical (RAE 1920: 480-481). Es este un problema de gran interés que también aparece en el tratado de fonología de Alarcos Llorach y trataremos con detenimiento en la sección siguiente, que atiende a las realizaciones antihiáticas en el sistema fonológico.

La edición de 1931 de la gramática académica comienza con la advertencia de que no han podido llevarse a cabo las reformas planeadas para la sección de prosodia y repite lo expresado acerca del antihiatismo en la edición anterior (RAE 1931: 6, 454).

En su Fonología española, Alarcos Llorach ([1950] 1991: 151-152, 202) reitera la frecuencia de la articulación de medias y abierta en contigüidad, señalando su analogía con el diptongo, con la diferencia de que solo las vocales cerradas $i$ y $u$ pueden ser margen de sílaba, o seminúcleo, como sucede en el diptongo, si bien admite que "otras vocales pueden reunirse en una sola sílaba", lo que despierta el interrogante sobre la posible capacidad de otros fonemas vocálicos para formar margen o seminúcleo silábico. Décadas más tarde, en su gramática, vuelve a mencionar la frecuencia del antihiatismo y su carácter común al habla cotidiana y al verso (Alarcos Llorach 1999: 43, 47-48).

El Esbozo de la Real Academia (1973: 5-6, 89-101), carente de validez normativa según se nos advierte en sus primeras páginas, amplía y modifica la parte de fonología, dando cabida a la fonología sintáctica bajo cuyo epígrafe estudia las combinaciones de sonidos vocálicos resultantes en sinalefa y sinéresis, fenómenos a los que 
concede amplia atención con numerosos ejemplos tomados de versos. Observa que el acento de intensidad no impide la unión silábica, incluso en posición final de enunciado, al tiempo que aprecia que, "en la dicción rápida y natural y no especialmente afectada”, las combinaciones que parecen propiciar la articulación hiante suelen resolverse mediante unión antihiática. Emplea el término diptongo para casos de sinéresis como los de náusea, abogaba, abora, abi... acerca de los que afirma que, en el habla, prevalece el antihiatismo; contempla la transformación de vocal media en cerrada como "vulgarismo" presente "en algunos territorios, sobre todo americanos".

Alcina y Blecua (1975: 416-419) observan una superioridad estadística del antihiatismo que refleja "una tendencia muy fuerte" que asocian a nivel de instrucción del hablante y a situación comunicativa: “es más popular en el nivel inculto y también puede aparecer en el habla culta de tipo familiar".

Desde el campo de la fonética, Martínez Celdrán (1984: 372) y Gili Gaya (1988: 117) hacen referencia a esta tendencia señalada en la gramática de Alcina y Blecua; Gili Gaya destaca su presencia en nuestra lengua "desde antiguo". Quilis ([1993] 1999: 65-66, 190) explica dos causas, una estructural y otra fisiológica, de la tendencia antihiática: el hecho de que las vocales, al ser articulaciones abiertas, encuentran dificultad para constituir límite de sílaba, a diferencia de las consonantes, en lo que se refiere a estructura silábica; y en lo fisiológico, el principio de economía, que favorece la articulación tautosilábica dado que implica menor consumo de aire en la dicción.

La Real Academia y la Asociación de Academias de la Lengua Española parecen seguir en su Diccionario panbispánico de dudas (DPD) (2005) las observaciones de Eduardo de la Barra al describir las combinaciones antihiáticas como alteración de las vocales medias, que se transformarían en cerradas: "[akordión] por acordeón, [kuéte] por cobete”, asociando esta diptongación de hiatos a "hablantes poco instruidos", aunque afirma que "se da también en el nivel culto" en América, "particularmente en México”, y mantienen la postura, ya presente en la gramática de 1920, de considerar hiato, desde el punto de vista normativo, toda combinación entre 
vocales medias o abierta (2005: 339). Llama nuestra atención que los ejemplos aportados por las Academias en este volumen se corresponden con casos en los que la sinéresis resulta abrupta, dado que se trata de hiatos favorecidos por acento de intensidad, sobre todo en la dicción aislada, fuera del contexto de una frase; extraña no encontrar ejemplos de tautosilabación más fácil y recurrente, como los presentados por otros tratadistas a lo largo de las páginas anteriores de este trabajo: Bilbao (Anónimo de Lovaina), poesía (Villar), almohada (García del Pozo), línea (Martínez López), óleo (De la Barra).

Gómez Torrego (2007: 35) presenta otros ejemplos de palabras que en la escritura son esdrújulas, pero en el habla son llanas: línea, béroe, espontáneo, área, a los que podemos sumar cráneo, núcleo, mediterráneo, idóneo; ya en latín las terminaciones -eus, -ea y -eum se tenían por tautosilábicas (Cecarelli 1999: 38), por lo que no habría de sorprender que esta articulación antihiática se haya mantenido en español.

En el volumen de fonética y fonología de la Nueva gramática, a diferencia del DPD, las Academias (2011: 339, 353) presentan en sus ejemplos de antihiatismo también la articulación sin transformación de vocales medias en cerradas: ['tea.tro], ['koe.te]; aseveran que "los resultados de esta tendencia antihiática no son generales y presentan diversos grados de aceptación social”, y que dependen de factores diatópicos, diastráticos y diafásicos, que condicionan "el esmero en la pronunciación”.

Con respecto a la transformación de medias en cerradas, además de las impresiones de Eduardo de la Barra en el siglo XIX, contamos con el testimonio de Frago García (1996: 26) de su presencia entre hablantes cultos de Venezuela y de Alarcos Llorach (1999: 47-48) acerca de hablantes cultos en diferentes países americanos, así como las Academias (2005: 339) destacan el caso de hablantes cultos de México. Hay estudios sobre el cambio de identidad de las vocales medias en diferentes comunidades de hablantes, como los de Alba (2006) en Nuevo México o Garrido (2009) en Colombia; resultan de gran interés al respecto las observaciones de Navarro Gala (2003: $67,137)$ sobre el reflejo de estas articulaciones en la escritura de 
Guamán Poma, achacadas a influencia del sustrato quechua, dado que en el sistema fonológico de esta lengua no existen los fonemas correspondientes a /e/ y /o/ en castellano, aspecto sobre el que, creemos, interesaría investigar en profundidad.

En definitiva, para concluir esta sección de nuestro trabajo, se ha registrado el antihiatismo en el habla española desde las primeras gramáticas de la misma hasta nuestros días; Nebrija, las ediciones iniciales de la gramática de la Real Academia, De Arrúe y Salleras describen la sinalefa como elisión de una de las vocales, mientras que el resto de tratadistas consultados, al igual que la Real Academia desde su edición de 1870, contemplan la articulación de las distintas vocales implicadas en un mismo impulso silábico; también se ha observado la transformación de vocales medias en cerradas, como vemos principalmente en De la Barra y en el DPD de las Academias.

Con variedad de valoraciones, como cabe esperar, los distintos autores consultados parecen estar de acuerdo en la regularidad de las articulaciones antihiáticas en nuestro idioma, si bien hay mayor discrepancia con respecto a la sinéresis, como también sucede entre los estudiosos de la versificación, según vimos en la sección primera. Las Academias, máxima autoridad normativa de nuestra lengua, determinan que las combinaciones de vocales medias o abierta son hiato, aunque observan la fuerte tendencia a articular dichas combinaciones en una misma sílaba, sin que ello implique transmutación de los fonemas /e/ y /o/ en /i/ y /u/, respectivamente.

Ello da lugar a un problema, formulado por la Real Academia en su edición de 1920: las combinaciones tautosilábicas entre vocales medias o abierta se explican en la rítmica, en la versificación, pero no gramaticalmente como se explica el diptongo; Alarcos Llorach también aludió al problema desde la fonología, recordando que solo las vocales cerradas pueden constituir margen o seminúcleo en la sílaba. Puesto que la gramática contempla que las vocales medias solo pueden ser núcleo silábico, resulta imposible explicar que estas se combinen entre sí o con la abierta para formar una sola sílaba. 


\section{El antihiatismo en el sistema fonológico: conciliación de precepto literario y norma gramatical}

En la estructura de la sílaba, los alófonos de las vocales cerradas /i/ y /u/ implicados en diptongos y triptongos quedan clasificados como marginales, paravocales o satélites, a diferencia de las vocales medias o abierta que constituyen el núcleo silábico (RAE y ASALE 2011: 25, 333, 345). Esta capacidad seminuclear o marginal ${ }^{4}$ de las vocales cerradas también se refleja en las denominaciones de vocoides, sonantes de deslizamiento, vocales con articulación de cierre, deslizadas (Aguilar Cuevas 2005: 122) o, comúnmente, semivocales y semiconsonantes (Navarro Tomás 1918: 54).

Alarcos Llorach ([1950] 1991: 151-160) resolvió las dudas que, acerca de la identidad vocálica o consonántica de estos alófonos, generaba la capacidad de las vocales cerradas para cumplir con función marginal en la sílaba, concluyendo que en efecto son dos fonemas vocálicos los que se combinan en una misma sílaba en el caso de diptongos; esto conduce a considerar que la naturaleza vocálica de los alófonos de vocales medias en combinaciones tautosilábicas entre sí o con abierta no impide que estas también desempeñen función de margen o seminúcleo silábico: el análisis fonético ha mostrado que la articulación de vocales marginales o seminucleares, tanto en diptongos $(/ \mathrm{i} /, / \mathrm{u} /)$ como en sinalefa y sinéresis $(/ \mathrm{e} /, / \mathrm{o} /)$, presenta los mismos rasgos de inestabilidad y transición formántica, como han señalado Navarro Tomás ([1918] 1926: 66) o, más recientemente, Aguilar Cuevas (2006: 366-367). Ello concuerda con las observaciones del Anónimo de Lovaina, Correa y Villar, en los siglos XVI y XVII, acerca de la percepción de las vocales medias que ejercerían como margen o seminúcleo en secuencias tautosilábicas, según hemos citado en el apartado anterior.

\footnotetext{
4 Mientras Alarcos Llorach ([1950] 1991: 160) y Quilis ([1993] 1999: 182) defienden que, en los diptongos, la vocal cerrada forma parte del margen silábico; Alcina y Blecua (1975: 263-264) y las Academias (2011: 332-335) la incluyen como constituyente, ascendente o descendente, del núcleo. En este trabajo, consideramos ambos puntos de vista.
} 
Las Academias (2011: 333, 343) explican la diferencia entre vocal nuclear y marginal desde la perspectiva de su sonoridad: la nuclear constituye la cima sonora de la sílaba, mientras que la marginal consiste en un ascenso de sonoridad previo a la cima o en un descenso posterior, lo que es evidente tanto en el caso de los diptongos como en el de las articulaciones antihiáticas de vocales medias entre sí o con abierta.

Sin embargo, si se restringe la capacidad de desempeñar función marginal únicamente a las vocales cerradas, forzosamente se entiende que las agrupaciones entre medias y abierta solo pueden ser hiato, dado que las distintas vocales implicadas habrían de constituir cima de sonoridad de una sílaba, aunque desde antiguo se haya observado lo contrario, según podemos comprobar en los apartados anteriores, lo que suscita una contradicción entre la descripción gramatical y la realidad oral.

Así cobra sentido la afirmación de que las articulaciones antihiáticas obedecen a "leyes de acento y ritmo" pero no a "ley gramatical”, como expresa la Real Academia en sus gramáticas de 1920 y 1931: si no se contempla la facultad de las vocales medias para actuar como marginales, es imposible ofrecer explicación gramatical del antihiatismo que se manifiesta en nuestro idioma por medio de sinalefa y sinéresis. Parece ser que este mismo problema encuentra Alarcos Llorach, según hemos referido en el apartado anterior, al constatar en su Fonología que vocales medias y abierta pueden combinarse en una misma sílaba, pero insistir en que solo las cerradas pueden denominarse marginales.

Sin embargo, Contreras (1969: 60) ha empleado la denominación de deslizadas para las vocales medias en casos de unión silábica, lo que coincide con la descripción dada por la Academia en su Esbozo de "diptongos" para las combinaciones tautosilábicas de medias entre sí o con abierta, así como su descripción, sin llegar a denominarlas marginales, de las medias para constituir tanto núcleo, por sí mismas, como seminúcleo, en combinación con otra más sonora, en la sílaba (RAE 1973: 13, 27).

Según se explica en el Esbozo (RAE 1973: 58-59), las combinaciones antihiáticas mediante sinéresis y sinalefa son "diptongos sin 
/i/, /u/", cuya diferencia con el diptongo tal como lo conocemos, en el que figura vocal cerrada, es que pueden articularse mediante hiato cuando recae acento (o cuando el hablante así lo disponga, según necesidades expresivas, como han observado Fernando de Herrera o Tomás Navarro Tomás, entre otros).

Parece, en definitiva, que en el sistema fonológico de nuestro idioma las vocales medias pueden desempeñar función seminuclear o marginal en la estructura de la sílaba, de acuerdo con su posición en la escala de sonoridad, según se notó ya en la Gramática académica de 1870; ello explica la normalidad con que, tal como se constata en la mayoría de tratados consultados en este trabajo, las vocales medias se combinan entre sí o con la abierta en un mismo impulso silábico en el habla. Sin embargo, la norma gramatical no contempla esta capacidad deslizante de las vocales medias, lo que impide la comprensión del antihiatismo desde el punto de vista normativo y da lugar a una contradicción entre preceptiva literaria, en la que la realización antihiática es norma, y gramática normativa, en la que se sostiene la normalidad del hiato.

Esta contradicción, difícilmente sostenible, se materializa en las posturas de los distintos tratadistas y podría favorecer aparentes vacilaciones en el tratamiento que ha recibido el asunto desde las Academias: la diferente actitud entre la primera Ortografía y la primera Gramática al respecto, por ejemplo, o las aproximaciones favorables que se hallan en la edición de 1870 y, sobre todo, en el Esbozo; la edición actualmente en vigor, específicamente el volumen de Fonética y fonología de 2011, presenta aún un juicio normativo desfavorable al antihiatismo, pero, al mismo tiempo, una descripción ajustada a la naturalidad del mismo que ilustra continuidad en la reflexión sobre este asunto en el que confluyen realidad oral y estudio gramatical, reflexión que, entendemos, ha de pasar por la aceptación gramatical de la facultad que presentan las vocales medias, en el sistema fonológico de nuestra lengua, para desempeñar la función de deslizadas. 


\section{Referencias bibliográficas}

Aguilar Cuevas, Lourdes

2005 "A vueltas con el problema de las vocales y las semiconsonantes”. Verba. 32, 121-142.

2006 "A propósito de las combinaciones vocálicas". Nueva Revista de Filología Hispánica. 54, 2, 353-381.

Alarcos Llorach, Emilio

[1950]1991 Fonología española. Cuarta edición. Madrid: Gredos.

1999 Gramática de la lengua española. Madrid: Espasa.

Alba, Matthew

2006 "Accounting for variability in the production of Spanish vowel sequences". En Selected Proceedings of the $9^{\text {th }}$ Hispanic Linguistics Symposium. Eds. Nuria Sagarra y Almeida Jaqueline Toribio. Sommerville: Cascadilla Proceedings Project, 273-285.

Alcina, Juan y José Manuel BlecuA

1975 Gramática española. Barcelona: Ariel.

AlLeN, William

1978 Vox Latina. A Guide to the Pronunciation of Classical Latin. Cambridge: Cambridge University Press.

ANÓNIMO

1555 Útil y breve institución para aprender los principios y fundamentos de la lengua española. Lovaina: Bartholomeus Gravius.

ARPA y LÓPEZ, Salvador

1888 Compendio de retórica y poética o literatura preceptiva. Madrid: Sucesores de Rivadeneyra.

Ballot, José Pablo

1845 Gramática de la lengua castellana dirigida a las escuelas. Barcelona: Juan Fco. Piferrer.

BAEHR, Rudolf

1984 Manual de versificación española. Madrid: Gredos.

BĚLIČ, Oldřich

2000 Verso español y verso europeo. Introducción a la teoría del verso español en el contexto europeo. Bogotá: Publicaciones del Instituto Caro y Cuervo. 
BELlo, Andrés

1835 Principios de ortología y métrica de la lengua castellana. Santiago de Chile: Imprenta de La Opinión.

BENOT, Eduardo

1898 Prosodia castellana y versificación. Madrid: Casa Editorial Juan Muñoz.

Blecua, José Manuel

1977 Sobre el rigor poético en España y otros ensayos. Barcelona: Ariel.

Callejón y Asme, José

1888 Elementos de literatura preceptiva o de retórica y poética. Sevilla: Imprenta de José $\mathrm{M}^{\mathrm{a}}$ Ariza.

CANo, Juan

1931 "La importancia relativa del acento y de la sílaba en la versificación española”. The Romanic Review. 22, 223-233.

Calleja, Juan Manuel

1818 Elementos de gramática castellana. Bilbao: Pedro Antonio de Apráiz.

Carpintero Moreno, Heliodoro

1906 Lecciones de preceptiva literaria. Alicante: Establecimiento tipográfico de Antonio Reus.

Cecarelli, Lucio

1999 Prosodia y métrica del latín clásico. Sevilla: Universidad de Sevilla.

Clarke, Dorothy

1995 "Fortuna del hiato y de la sinalefa en la poesía lírica castellana del s. XV”. Bulletin Hispanique. 57, 129-132.

Coll y Vehí, José

1856 Elementos de literatura. Madrid: Imprenta y Estereotipia de M. Rivadeneyra.

CONTRERAs, Heles

1969 "Vowel Fusion in Spanish". Hispania. 52, 1, 60-62.

Correa, Gonzalo

1625 Arte de la lengua española castellana. Manuscrito disponible en la Biblioteca Nacional de España. Consultado: 19 
de junio de 2019. <http://bdh.bne.es/bnesearch/CompleteSearch.do?field=todos\&text=arte+de+la+lengua + castellana + espa \% C3\%B1ola\&showYearItems=\&exact=on\&textH=\& advanced $=$ false\&completeText $=\&$ pageSize $=1 \&$ pageSizeAbr $\mathrm{v}=30$ \&page Number $=1>$

De Arrúe, Alejandro

1842 Gramática española elemental. Bilbao: Imprenta de Depont.

De Balbín, Rafael

1968 Sistema de rítmica castellana. Madrid: Gredos.

De Herrera, Fernando

1580 Obras de Garcilaso de la Vega con Anotaciones de Fernando de Herrera. Sevilla: Alonso de la Barrera.

De la Barra, Eduardo

1894 Problemas de fonética resueltos según un nuevo método. Buenos Aires: Félix Lajouane Editor.

De Mas, Sinibaldo

1843 Sistema musical de la lengua castellana. Barcelona: Imprenta de A. Bergnes y Cía.

De Masdéu, Juan Francisco

1801 Arte poética fácil. Gerona: Imprenta de Antonio Oliva.

De Sicilia, Mariano José

1832 Lecciones elementales de ortología y prosodia. Madrid: Imprenta Real.

Díaz Rengifo, Juan

1592 Arte poética española. Salamanca: Casa de Miguel Serrano de Vargas.

Domínguez Caparrós, José

1975 Contribución a la bistoria de las teorías métricas en los siglos XVIII y XIX. Madrid: CSIC.

2001 Diccionario de métrica española. Madrid: Alianza.

DPD = Real Academia Española y Asociación de Academias de la LENGUA EsPaÑOLA

2005 Diccionario panbispánico de dudas. Madrid: Santillana. 
FERNÁNDEZ MONJE, Isidoro

1854 Curso elemental de la lengua española. Madrid: Librería de León Pablo Villaverde.

Frago García, Juan Antonio

1996 "Dialectología e historia de la lengua”. En Manual de dialectología hispánica. El español de España. Ed., Manuel Alvar. Barcelona: Ariel, 22-30.

García Calvo, Agustín

2006 Tratado de rítmica y prosodia y de métrica y versificación. Zamora: Lucina.

García del Pozo, Gregorio

1825 La doble ortología castellana, o correspondencia entre la pronunciación y la escritura de este idioma. Madrid: Imprenta de E. Aguado.

GARRIDO, Marisol

2009 Diphthongation of Non-High Vowel Sequences in Latin-American Spanish. Anne Habour: ProQuest.

Gil de ZÁrate, Antonio

1850 Principios generales de poética y retórica. Madrid: Imprenta de Martínez y Menuesa.

Gili Gaya, Samuel

1988 Elementos de fonética general. Madrid: Gredos.

Gómez Hermosilla, José

1826 Arte de hablar en prosa y verso (volumen 2). Madrid: Imprenta Real.

GÓMEZ TORREgo, Leonardo

2007 Hablar y escribir correctamente. Gramática normativa del español actual. Madrid: Arco Libros.

GonzÁlez Portilla, Bruno

1831 Elementos de prosodia de la lengua castellana. Puerto Príncipe: Imprenta del Gobierno y Real Hacienda.

Hanssen, Federico

1897 "Miscelánea de versificación castellana". Anales de la Universidad de Chile. 97, 227-274. 
1900 "Notas a la prosodia castellana". Anales de la Universidad de Chile. 107, 315-335.

JAIMES Freyre, Ricardo

1919 Leyes de la versificación castellana. La Paz: Imprenta Artística.

LAUSBERG, Heinrich

1998 Handbook of Literary Rhethoric: A Foundation for Literary Study. Leiden: Brill.

López Bastarán, Manuel

1889 Retórica y poética o literatura preceptiva. Huesca: Establecimiento Tipográfico Oscense.

LÓpez Grijera, Luisa

1994 "Fonética y retórica en el siglo XVI". En Sin fronteras. Homenaje a María Josefa Canellada. Eds. Berta Pallares, Pedro Peira y Jesús Sánchez Lobato. Madrid: Editorial Complutense, 349357.

LÓPEZ de VeLasco, Juan

1582 Ortografía y pronunciación castellana. Burgos: Felipe de Junta.

López Pelegrín, Santos, Pedro De Oliva y Juan Peñalver

1872 Nuevo diccionario de la lengua castellana. París: Librería de Rosa y Bouret.

LOZANO, Carmen

2006 "La métrica latina desde Pastrana a Nebrija". Revista de Poética Medieval. 17, 215-248.

Marroquín, José Manuel

1893 Lecciones elementales de retórica y poética. Bogotá: Librería Colombiana.

Martínez Celdrán, Eugenio

1984 Fonética. Barcelona: Teide.

Martínez López, Pedro

1841 Principios de la lengua castellana o prueba contra todos los que asienta D. Vicente Salvá en su gramática. Madrid: Librería de la Viuda de Calleja e Hijos.

Milá y Fontanals, Manuel

1888 Tratados doctrinales de literatura. Barcelona: Librería de Álvaro Verdaguer. 
Monláu, Pedro

1842 Elementos de literatura o arte de componer en prosa y verso. Barcelona: Imprenta y librería de Pablo Riera.

Navarro Gala, Rosario

2003 Lengua y cultura en la "Nueva corónica y buen gobierno". Aproximación al español de los indígenas en el Perú de los siglos XVI-XVII. Valencia: Universidad de Valencia.

Navarro y Ledesma, Francisco

1901 Nociones de gramática práctica de la lengua castellana. Madrid: Imprenta Moderna.

Navarro Tomás, Tomás

1918 Manual de pronunciación española. Madrid: Centro de Estudios Históricos.

[1918] 1926 Manual de pronunciación española. Tercera edición. Madrid: Centro de Estudios Históricos.

[1956] 1974 Métrica española. Reseña histórica y descriptiva. Quinta edición. Madrid: Guadarrama.

1959 Arte del verso. México D. F.: Compañía General de Ediciones.

Nebrija, Antonio de

1492 Arte de la lengua castellana. Salamanca: Juan de Porras.

Paraíso Almansa, Isabel

2000 La métrica española en su contexto románico. Madrid: Arco Libros.

Pla Colomer, Francisco Pedro

2019 "Consideraciones en torno al verso alejandrino desde la historia de la lengua”. Tonos Digital. 36, 1-32. Consultado: 4 de julio de 2019. <http://www.tonosdigital.es/ojs/index.php/ tonos/article/view/2124/1051>

Quilis Merín, Mercedes

1991 "Más sobre latín tardío y romance temprano". Anuario del Seminario de Filología Vasca "Julio Urquijo". XXV, 3, 797803.

QuiLis, Antonio

1984 Métrica española. Barcelona: Ariel.

[1993] 1999 Tratado de fonética y fonología españolas. Segunda edición. Madrid: Gredos. 
Real Academia Española

1741 Ortografía española. Madrid: Imprenta de la Real Academia Española.

1771 Gramática de la lengua castellana. Madrid: Imprenta de D. Joaquín de Ibarra.

1854 Gramática de la lengua castellana. Madrid: Imprenta Nacional.

1870 Gramática de la lengua española. Madrid: Imprenta y Estereotipia de M. Rivadeneyra.

1920 Gramática de la lengua castellana. Madrid: Perlado, Paéz y Cía.

1931 Gramática de la lengua española. Madrid: Espasa-Calpe.

1973 Esbozo de una nueva gramática de la lengua española. Madrid: Espasa-Calpe.

Real Academia Española y Asociación de Academias de la Lengua ESPAÑOLA

2011 Nueva gramática de la lengua española: Fonética y fonología. Barcelona: Espasa.

Salleras, Matías

1876 Gramática razonada de la lengua española. Segovia: Imprenta de Pedro Ondero.

Salvá, Vicente

[1827] 1852 Gramática de la lengua española según abora se babla. Novena edición. París: Librería de Garnier Hermanos.

SÁnCHEZ de Lima, Miguel

1580 Arte poética en romance castellano. Alcalá de Henares: Casa de Juan Íñiguez Lequerica.

Solana Pujalte, Julián

1987 Análisis métrico-prosódico de la poesía de Alcuino de York. Tesis doctoral. Universidad de Sevilla.

SPANG, Kurt

1983 Ritmo y versificación. Teoría y práctica del análisis métrico y ritmico. Murcia: Universidad de Murcia.

Torre Serrano, Esteban

1999 El ritmo del verso: estudios sobre el cómputo silábico y la distribución acentual a la luz de la métrica comparada, en el verso español moderno. Murcia: Universidad de Murcia. 
2013 “Zeuxis y azeuxis. Más sobre vocales en contacto”. Rhythmica. 11, 187-205.

URía MaQua, Isabel

1986 "Gonzalo de Berceo y el Mester de Clerecía en la nueva perspectiva de la crítica”. Berceo. 110-111, 7-20.

VILlaR, Juan

1651 Arte de gramática española. Valencia: Francisco Verengel.

Recibido: 08/11/2019

Aceptado: 11/02/2020 